
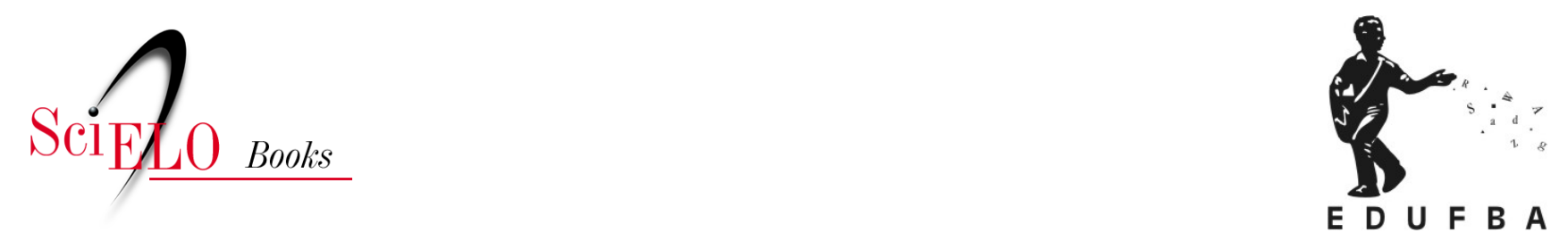

\title{
Focalização como contraponto entre desigualdade e pobreza
}

\author{
José Carlos da Exaltação Torres
}

\section{SciELO Books / SciELO Livros / SciELO Libros}

TORRES, J.C.E. Focalização como contraponto entre desigualdade e pobreza. In: Cadastro Único: tecnologia de reclassificação social [online]. Salvador: EDUFBA, 2016, pp. 81-97. ISBN: 978-65-5630011-5. https://doi.org/10.7476/9786556300115.0007.

International license.

Todo o conteúdo deste trabalho, exceto quando houver ressalva, é publicado sob a licença Creative Commons Atribição 4.0. 


\section{FOCALIZAÇÃO COMO CONTRAPONTO ENTRE DESIGUALDADE E POBREZA}

Em artigo intitulado "Desigualdade e pobreza no Brasil”, Barros, Henriques e Mendonça (2000) analisam a tendência histórica do país à manutenção das desigualdades e da pobreza, de persistente exclusão à dignidade e à cidadania. O trabalho busca descrever o presente e o passado da pobreza e das desigualdades no Brasil, considerando as interrelações causais entre ambas, no intervalo compreendido entre os anos 1977 e 1998. Os autores querem demonstrar a viabilidade econômica do país para a erradicação da pobreza e ressaltar a precedência das políticas redistributivas sobre as de crescimento econômico nesse processo. $\mathrm{O}$ artigo está fundamentado numa hipótese central, composta por dois pressupostos básicos:

a. o Brasil não é um país pobre, mas um país com muitos pobres”;

b. o principal determinante da pobreza no Brasil está na distribuição desigual da renda e "das oportunidades de inclusão econômica e social”. (BARROS; HENRIQUES; MENDONÇA, 200o, p. 123)

Entende-se, assim, que a redução das desigualdades deve ser a prioridade no desenho das políticas de combate à pobreza no país.

Os autores definem pobreza como "situações de carência em que os indivíduos não conseguem manter um padrão mínimo de vida condizente com as referências socialmente estabelecidas em cada contexto histórico" (BARROS; HENRIQUES; MENDONÇA, 200o, p. 124), contudo, para fins operacionais, consideram-na sob uma perspectiva específica, a "insuficiência 
de renda", e sua avaliação obedecerá ao estabelecimento de uma "linha de pobreza": "há pobreza apenas na medida em que existem famílias vivendo com renda familiar per capta inferior ao nível mínimo necessário para que possam satisfazer suas necessidades mais básicas”. (BARROS; HENRIQUES; MENDONÇA, 200o, p. 124)

Analisando dados extraídos da Pesquisa Nacional por Amostra de Domicílios (PNAD), do Instituto Brasileiro de Geografia e Estatística (IBGE), os autores observaram que em 1998 havia um contingente de 50 milhões de brasileiros vivendo em situação de pobreza, o que compreendia 1/3 da população brasileira, dentre os quais, 21 milhões em situação de indigência. A evolução dos índices de pobreza, no período de 1977 a 1998, acompanhou a dinâmica macroeconômica, a exemplo do verificado à época da recessão, entre 1983 e 1984, com 51\% e 50,4\% respectivamente, e da implantação dos planos econômicos Cruzado e Real, em 1986, com 28,2\% e em 1995, com $33,9 \%$ respectivamente, estas as mudanças mais significativas do intervalo observado, no último caso com resultados sustentados até o final da série. Entre 1977 e 1998, houve uma pequena redução de 39\% para 33\%, mas considerando a evolução demográfica, em números absolutos, houve também um incremento de cerca de 10 milhões de pessoas, o que coincide, por outro lado, com o número de pessoas que saíram da pobreza a partir do Plano Real (BARROS; HENRIQUES; MENDONÇA, 2000, p. 125). Os autores consideram, assim, que a década de 1990 apresenta tendência à manutenção de níveis mais brandos de pobreza, mas ainda "moralmente" inaceitáveis, em razão do potencial econômico do país.

Consideram-se a "escassez de recursos" e a "distribuição desigual” como fatores determinantes imediatos da pobreza. A primeira dimensão, a noção de "escassez", é analisada sob três critérios: "a comparação do Brasil com o resto do mundo, a análise da estrutura da renda média do país e, finalmente, o exame do padrão de consumo médio da família brasileira”. (BARROS; HENRIQUES; MENDONÇA, 200o, p. 126) Desta perspectiva, observa-se que $64 \%$ dos países têm renda per capta menor que a do Brasil, os quais conformam cerca de $77 \%$ da população mundial, pelo que a população brasileira não pode ser classificada dentre as mais pobres do mundo. "A comparação internacional quanto a renda per capita coloca o Brasil entre o terço mais rico dos países do mundo e, portanto, não nos permite considerá -lo um país pobre”. (BARROS; HENRIQUES; MENDONÇA, 200o, p. 126) Observa-se, contudo, que "comparado aos países industrializados o Brasil 
não é um país rico mas, comparado a outros países em desenvolvimento, estaria, a princípio, entre os que apresentam melhores condições de enfrentar a pobreza de sua população”. (BARROS; HENRIQUES; MENDONÇA, 2000, p. 126)

Esses autores explicam que a posição razoável do Brasil em relação a indicadores internacionais deve-se mais à situação externa que à sua própria, ou seja, está entre os melhores quanto ao volume de recursos de que dispõe, mas entre os piores no que tange à sua distribuição, este sendo o principal fator explicativo da intensidade da pobreza, como atesta a comparação com países de renda per capta semelhante, onde a pobreza atinge cerca de $10 \%$ da população, contra os 30\% do Brasil. (BARROS; HENRIQUES; MENDONÇA, 200o, p. 127) Considerando a estrutura de renda e pobreza nos países observados, os autores estabelecem uma "norma internacional" de determinação do quantitativo de pobres, pelo que concluem que mais de dois terços da pobreza brasileira decorrem de sua elevada desigualdade na distribuição de renda. Em suas palavras:

De fato, considerando a renda e o grau de pobreza reportados pelos países no Relatório de desenvolvimento humano, podemos definir uma norma internacional que imputaria um valor previsto de somente $8 \%$ de pobres para países com a renda per capita equivalente à brasileira. Assim, caso o grau de desigualdade de renda no Brasil correspondesse à desigualdade mundial média associada a cada nível de renda per capita, apenas $8 \%$ da população brasileira deveria ser pobre. Este valor seria, de modo consistente com a norma internacional, aquele que poderíamos associar estritamente à escassez agregada de recursos no país. Todo o restante da distância do Brasil em relação a esta norma - o valor nada desprezível de cerca de 22 pontos percentuais - deve-se, portanto, ao elevado grau de desigualdade na distribuição dos recursos nacionais. (BARROS; HENRIQUES; MENDONÇA, 200o, p. 127-128, grifo do autor)

Na subseção que trata do segundo critério de análise - estrutura da renda média do país -, os autores lançam duas questões que, a fundo, estruturam todo o texto: “é possível enfrentar a pobreza no Brasil?”, e, em seu desdobramento mais específico: "pode a sociedade brasileira, com a dotação de recursos que possui, erradicar a pobreza?”. (BARROS; HENRIQUES; MENDONÇA, 200o, p. 128) Para resposta à questão, lança-se mão de uma expressão que não é tratada conceitualmente no texto: "riqueza relativa", mas que se permite entender sua utilidade em razão da "relevância conceitual da relação entre as rendas auferidas pelos segmentos extremos 
de uma sociedade como um parâmetro econômico de justiça social”. (BARROS; HENRIQUES; MENDONÇA, 200o, p. 137) Construindo estimativas da evolução do Produto Interno Bruto (PIB) per capta e da renda familiar per capta entre 1977 e 1998, os autores verificam que os valores encontrados variam de cinco a oito vezes a linha de indigência, e de três a quatro vezes a linha de pobreza, pelo que concluem que "uma distribuição equitativa dos recursos nacionais disponíveis seria muito mais do que suficiente para eliminar toda pobreza”. (BARROS; HENRIQUES; MENDONÇA, 200o, p. 129) E neste sentido, propõem um exercício hipotético, onde:

[...] o poder público disporia da capacidade de identificar todos os indivíduos da população pobre e poderia transferir, com focalização perfeita e calibragem precisa entre as famílias, os recursos estritamente necessários para que todos esses indivíduos pobres obtivessem a renda equivalente ao valor da linha de pobreza. (BARROS; HENRIQUES; MENDONÇA, 200o, p. 129)

No exercício proposto, os recursos da transferência teriam como fonte a renda familiar. Assim, para erradicar a indigência - 14\% da população brasileira - um montante de R $\$ 6$ bi, ou $2 \%$ das rendas das famílias, deveria ser anualmente transferido a um público bem definido, focalizado. E, para superar toda a pobreza, transferir-se-ia $7 \%$ da renda familiar, ou R $\$ 29$ bi anualmente (8\% incluindo custos operacionais). (BARROS; HENRIQUES; MENDONÇA, 200o, p. 129) Os autores julgam ser possível também estimar a intensidade com que a pobreza se reduziria em consequência da redução das desigualdades. Simula-se, assim, mais um exercício, comparando os países latino-americanos. Toma-se o Uruguai, país menos desigual - Gini o,4 - para indicar que, reduzindo a desigualdade (sem afetar a renda média) ao nível daquele país, a pobreza brasileira cairia em $20 \%$. Afirmam os autores que "a partir desse exercício, podemos sugerir que quase dois terços da pobreza no Brasil podem estar associados ao diferencial no grau de desigualdade da distribuição de renda existente entre o Brasil e o Uruguai”. (BARROS; HENRIQUES; MENDONÇA, 2000, p. 130)

Para análise do padrão de consumo (terceiro critério), utilizam-se dados da Pesquisa sobre Padrões de Vida (PPV-IBGE) de 1996 e 1997, tendo como referência os $20 \%$ de famílias com renda per capta próxima à média nacional, com limites de 10\% imediatamente anterior e 10\% imediatamente posterior à média. A principal constatação é que a alimentação figura como 
item principal de consumo dessas famílias, aproximando-se a $47 \%$ do total dos valores; uma marca significativa em referência às linhas de indigência e de pobreza, das quais pode representar o quádruplo e o dobro, respectivamente. Observe-se, neste sentido, que a renda domiciliar per capta média representa seis vezes a indigência e três vezes a pobreza.

Para análise da desigualdade de renda, os autores: a) estabelecem comparação com outros países; e b) avaliam a evolução dessa desigualdade no período estudado. Para isso, utilizam-se de medidas tradicionais: coeficiente de Gini, índice de Theil e razão entre as rendas médias dos 10\% mais ricos com os $40 \%$ mais pobres, e dos $20 \%$ mais ricos com os $20 \%$ mais pobres, para dar conta do grau de justiça social correspondente a cada realidade. Num grupo de 92 países, o Brasil figura como o terceiro entre aqueles com maior desigualdade, com Gini próximo a o,6. Na razão entre a renda dos $10 \%$ mais ricos e os $40 \%$ mais pobres, num grupo de 50 países, o Brasil se destaca como o mais desigual de todos, pois os ricos têm renda até 28 vezes a renda dos pobres, situação confirmada na comparação entre os $20 \%$ mais ricos e os $20 \%$ mais pobres: o Brasil ostenta uma marca superior a 30 vezes a diferença. Diante desse quadro, os autores antecipam a conclusão, em confirmação a seus pressupostos iniciais, de que "o extraordinário grau de desigualdade de renda brasileiro encontra-se no núcleo da explicação do fato de o grau de pobreza no Brasil ser significativamente mais elevado que o de outros países com renda per capita similar”. (BARROS; HENRIQUES; MENDONÇA, 200o, p. 134)

A análise sobre a evolução das desigualdades internamente, sob os mesmos parâmetros, confirma esses dados, numa razão de 30 para 1 entre os 10\% mais e os $40 \%$ menos, e de 35 para 1 na relação entre os $20 \%$ mais e os $20 \%$ menos. O Gini alcança o,64, e o Theil, o,91, dados do final da década de 1980, em meio à instabilidade econômica. Há pequenas variações, mas pouco significativas, o que revela o dado mais importante: a desigual distribuição de renda no Brasil preserva um persistente nível de estabilidade.

Em resumo, os autores afirmam que no Brasil "vivemos uma perversa simetria social, em que os $10 \%$ mais ricos se apropriam de $50 \%$ do total da renda das famílias e, como por espelhamento, os 50\% mais pobres possuem cerca de $10 \%$ da renda". (BARROS; HENRIQUES; MENDONÇA, 200o, p. 137) Em conta disso, ressalta-se a importância de se redesenhar as “estratégias de enfrentamento à pobreza" (BARROS; HENRIQUES; MENDONÇA, 200o, p. 138) a partir da combinação entre crescimento econômi- 
co e redução das desigualdades distributivas, de modo a garantir velocidade e eficácia a esse processo.

Apresenta-se, assim, uma estimativa comparada do impacto que teriam alternativamente políticas de crescimento econômico e políticas de redução das desigualdades. Tendo como referência a extensão da pobreza e os níveis de desigualdade em outros países latino-americanos, verifica-se que uma alteração da desigualdade aos níveis do México, por exemplo, reduziria em nove pontos percentuais a pobreza no Brasil e, considerando como parâmetro a Costa Rica, a redução seria de 12,5\%. Quanto ao crescimento, estimando-se um saldo anual de $2,75 \%$, a redução da pobreza em $9 \%$ só ocorreria num intervalo mínimo de dez anos. Os 12,5\% em relação à Costa Rica só seriam atingidos, ao fim desse mesmo período, a um crescimento constante de $4 \%$. Ou seja, a via do crescimento econômico produz efeitos sobre a pobreza, mas num espaço de tempo muito dilatado. Conclui-se, assim, que "a pobreza reage com maior sensibilidade aos esforços de aumento da equidade do que aos de aumento do crescimento". (BARROS; HENRIQUES; MENDONÇA, 200o, p. 139)

Para esses autores, a experiência brasileira demonstra uma opção inversa, tendo o crescimento sempre como alternativa prioritária, fato demonstrado na decomposição das causas da redução da pobreza sobre a análise da renda familiar entre 1977 e 1997. Tomando-se como referência o ano de 1997, ao identificar-se aí o menor grau de pobreza do intervalo (à exceção de 1986, de caráter particular), verifica-se que todos os movimentos de queda da pobreza devem-se ao crescimento, pois a desigualdade de renda não cede aos movimentos da macroeconomia. Em razão disso, a estratégia de combate à pobreza no período mostrou-se ineficaz. Tendo isso em conta, os autores finalizam reafirmando a sua tese de que o Brasil não é pobre, mas injusto e desigual, por não ter assumido o que seria o "desafio clássico" da modernidade: a realização de um projeto social que combine democracia, eficiência econômica e justiça social. Pois não há no país escassez de recursos, mas uma persistente e intensa desigualdade de renda, com implicações não apenas sociais, mas morais sobre a nação. 


\section{A NOÇÃO DE JUSTIÇA SOCIAL COMO MEDIADORA DO DEBATE ENTRE FOCALIZAÇÃO E UNIVERSALIZAÇÃO}

A Constituição Federal Brasileira de 1988 promoveu a formalização da noção de universalização de direitos, uma perspectiva distinta da noção de focalização. Com base nisso, o debate sobre políticas sociais no Brasil, a partir da década de 1990, contrapõe essas duas vertentes: políticas universais versus políticas focalizadas. Os argumentos apresentados na defesa da universalidade orientam-se pelo princípio da equidade, enquanto a focalização remete-se ao princípio de maior eficiência na alocação dos benefícios sobre quem efetivamente necessita. Assim, cada uma dessas tendências sintetiza aspectos da oposição entre equidade e eficiência, no que tange à aplicação dos recursos públicos na área social. Embora o governo brasileiro, a partir da segunda metade da década de 1990, tenha feito uma opção cada vez mais clara pela focalização, com a implementação de programas sociais específicos neste período, o debate coloca-se num impasse, dado pela relação estabelecida entre essa escolha e os princípios constitucionais universalistas, concernentes à proteção social no país, debate esse, aliás, que pode ser resumido numa questão que transpassa todos os seus aspectos: "quem" é que tem "direito" aos benefícios dessas políticas? Ou "para quem" elas serão direcionadas? Ao definir isso, se definem também os critérios de formulação das políticas, de modo a se ter controle sobre o alcance de seus resultados.

Ponderando posições que possam parecer estanques entre essas duas perspectivas, Kerstenetzky (2006, p. 573) afirma que "apresentar a escolha entre focalização e universalização como uma eleição entre eficiência e equidade não esclarece a totalidade de opções no debate". Neste sentido, a autora discute os limites de cada perspectiva, as contradições presentes no debate e as possibilidades de aproximação ou combinação entre as perspectivas. Segundo a sua interpretação, o ponto de partida para a opção entre as duas alternativas deve ser a concepção acerca da noção de justiça social predominante: se justiça de mercado ou justiça distributiva (centrada no papel do Estado): “[...] a decisão sobre o estilo de política social, se focalizada ou universal, revela-se pouco clara na ausência de uma decisão prévia sobre princípios de justiça social que se quer implementar”. (KERSTENETZKY, 2006, p. 564)

Segundo Kerstenetzky (2006), a noção de justiça de mercado ("mercadocêntrica”) dá a este a função de distribuir as vantagens econômicas, 
e ao Estado, o zelo pelas condições do seu funcionamento. "Por um lado, a liberdade de escolha dos indivíduos seria maximizada, por outro, a eficiência econômica seria promovida, já que a alocação de recursos seria induzida exclusivamente pelos incentivos do mercado". (KERSTENETZKY, 2006, p. 565) Neste modelo, reserva-se, ainda, ao Estado a responsabilidade por instituir uma rede de proteção social, a exemplo das políticas de renda mínima e seguro desemprego, contra as incertezas inerentes às atividades econômicas. A concepção distributiva ("estadocêntrica”), por sua vez, atribui função complementar ao Estado no processo de distribuição dos recursos e vantagens resultantes das atividades econômicas, considerando que há influência de características "tais como classe, família, cor, gênero, etnia, habilidades e talentos inatos" (KERSTENETZKY, 2006, p. 566) na liberdade de escolha dos indivíduos, restringindo as suas oportunidades políticas, sociais e econômicas, as quais devem ser promovidas por políticas redistributivas, condicionadas, também, ao princípio da eficiência. Assim, a redistribuição de que trata esta concepção é de "oportunidades de realização", principalmente, mais social e política que econômica.

Exposta a noção de justiça social, Kerstenetzky (2006) discute os aspectos inerentes às duas perspectivas políticas (focalização e universalização). A focalização é apresentada em três aspectos distintos: residualismo, condicionalidade e ação reparatória. Como residualismo, a focalização refere-se à destinação das políticas sociais exclusivamente aos segmentos sociais excluídos da integração promovida pela justiça de mercado. "A verdadeira 'política social' seria, na verdade, a política econômica (que promove as reformas de orientação mercadológica, que no longo prazo seriam capazes de incluir [a] todos)". (KERSTENETZKY, 2006, p. 568) Nessa perspectiva, a principal justificativa para a intervenção pública seria o infortúnio, a pobreza proveniente do acaso. Assim, a política social subsume à lógica do mercado e afasta-se da noção de universalização de direitos, desvinculando-se da noção de equidade, de redução das desigualdades. "Na medida em que a política social sofre, nesta abordagem do problema, uma compartimentalização, seu vínculo com a noção de direitos sociais universais perde força, e ela se torna um coadjuvante do objetivo de eficiência econômica". (KERSTENETZKY, 2006, p. 569)

Como condicionalidade, a focalização busca atingir a eficiência na resolução de um problema específico, optando por um foco, pautada num conjunto de conhecimentos acerca da realidade - demográficos, sociológi- 
cos, territoriais e econômicos, além dos resultados de políticas anteriores, sendo a eficiência dos gastos, condição para novos investimentos. Por fim, a focalização como ação reparatória visa restituir o acesso a direitos formais universais a grupos que deles tenham sido afastados em razão da dinâmica mercadológica, de distribuição desigual de oportunidades, inclusive herdadas de gerações anteriores. Sua relação com direitos sociais universais a põe em complementaridade às políticas de universalização. Sob essa perspectiva, a focalização pode assumir foros de redistribuição compensatória, com distribuição de bolsas, bens e serviços, "resguardando o direito universal à vida” (KERSTENETZKY, 2006, p. 571); ou de redistribuição estrutural, implementando reformas profundas na estrutura distributiva, atingindo as desigualdades socioeconômicas, tornando efetiva a realização de direitos políticos, civis e sociais.

Quanto às políticas universais, a autora destaca que também essas se orientam por princípio de eficiência (eficiência social dos gastos sociais) e ética, notadamente na economia de recursos gastos com monitoramento, avaliações, e redesenhos que a focalização exige, além de custos intangíveis, como a criação de estigmas, sem contar os resultados políticos mais seguros ou garantidos na universalização. No que tange à ética, a universalização coletiviza os direitos de cidadania, prima pela igualdade e desvincula-se das determinações do mercado; predomina aí o Estado de Bem-estar.

\section{AJUSTE ECONÔMICO E ENFRENTAMENTO DA POBREZA SINTETIZADOS NA OPERAÇÃO DE PROGRAMAS SOCIAIS FOCALIZADOS}

É com base na noção de universalização que a Constituição Federal de 1988 é tomada por muitos como a expressão maior da efetiva redemocratização do Estado brasileiro; a Carta Magna de uma nação que põe em pé de igualdade todos os seus cidadãos, garantindo-lhes direitos homogêneos, numa resposta altiva ao seu passado de agruras, de cerceamentos e desigualdades. Dessa perspectiva, a promulgação da Constituição teria criado as condições para a ampliação e universalização dos direitos de cidadania no Brasil, mas a expectativa que criou foi de curtíssima duração, pois já na década de 1990 várias reformas foram adotadas, na linha de dissolução desses direitos, atendendo aos ajustes requeridos pelo modelo adotado na gestão 
político-econômica, o neoliberalismo, negligenciando, assim, a agenda social do país. (SILVA; YAZBEK; GIOVANNI, 2008)

Ao tratar desse tema, Anete Ivo (2008) considera que a consolidação dos direitos sociais no Brasil se deu tardiamente e coincidiu com um momento em que no cenário internacional dava-se um processo de redução do papel do Estado e crise nos sistemas de proteção social. ${ }^{15}$ Configura-se, assim, no contexto brasileiro, um quadro ambivalente entre inclusão e exclusão, que dará a tônica dos encaminhamentos para a resolução da "questão social”"16 no país. Para Ivo (2008, p. 187), durante os anos 1990 o tratamento da questão social no Brasil sofreu uma "reconversão" de sentido, saindo da perspectiva da "inclusão social universalizada e de proteção" para a operação de "programas mitigadores, setorializados e focalizados da pobreza".

Na década de 1990, o Brasil aderiu às condições impostas pela economia internacional para adequar-se aos movimentos de uma economia competitiva global, e os ajustes requeridos nesse processo incidiram negativamente sobre os direitos sociais postulados pela Constituição. Para Graça Druck (1996, p. 29), esse fato corresponde às determinações do "projeto político neoliberal”, representado nas proposições do "Consenso de Washington" para a consolidação de sua hegemonia mundial, cujos objetivos principais resumem-se em "estabilização da economia (corte no déficit público, combate à inflação)”, “'reformas estruturais' com redução do Estado”, dando permissividade às privatizações, à "desregulação dos mercados e liberalização financeira e comercial” e ao crescimento econômico condicionado à "abertura da economia" ao capital estrangeiro. (DRUCK, 1996, p. 30)

Em verdade, esse cenário articula três processos que fazem parte de um mesmo movimento: a reestruturação produtiva, a globalização da economia e a assunção do projeto neoliberal. Como afirma Druck (1996, p. 29),

15 Embora desenvolva esse tema de uma perspectiva mais ampla em 2008, Ivo já o pôs em discussão desde 2004.

16 Basicamente, a existência de uma questão social põe em evidência as dificuldades de uma sociedade para atender às exigências que lhes são inerentes, remete à correspondência entre seus estatutos formais e as condições objetivas de realização. Robert Castel (1998, p. 30), buscando uma definição para o tema, afirma que essa questão é "um desafio que interroga, põe em questão a capacidade de uma sociedade [...] para existir como um conjunto ligado por relações de interdependência". Classicamente, a questão social corresponde à constatação do "divórcio entre uma ordem jurídico-política, fundada sobre o reconhecimento dos direitos dos cidadãos, e uma ordem econômica que acarreta uma miséria e uma desmoralização de massa”. 
“o neoliberalismo é um projeto político e econômico e constitui o arcabouço ideológico ideal para consolidar a reestruturação produtiva no contexto da globalização"; assim, é da perspectiva da globalização que esses processos se instauram como a consagração de um novo estágio de desenvolvimento do modo de produção capitalista. Aos auspícios da globalização, deflagramse transformações de caráter econômico, social, político e cultural. Em tese, com a consolidação da reestruturação produtiva, que propicia uma pujante renovação dos parques tecnológicos, constroem-se as condições para o desenvolvimento e o crescimento da economia, mas simultaneamente promove-se uma verdadeira revolução na divisão do trabalho, reduzindo significativa e irreversivelmente os postos empregatícios, com consequências nefastas sobre as condições de vida da classe trabalhadora, redundando no incremento e no aprofundamento da pobreza e da miséria.

É ainda nesse contexto que se verifica o surgimento de empresas de micro, pequeno e médio porte nos setores produtivo e de serviços, funcionando como "redes de subcontratação" (DRUCK, 1996, p. 23), num processo de terceirização de atividades das grandes empresas e mesmo do Estado. Nessa rede, opera-se uma verdadeira reformulação das relações de produção, com extensiva precarização tanto das condições, quanto das relações e remuneração do trabalho. Na esfera macro, a globalização representa, ainda, uma "radicalização dos processos de concentração e centralização de capitais" (DRUCK, 1996, p. 23) e subsequente supremacia do capital financeiro sobre o produtivo, o que nas economias menos consolidadas leva à instauração de forte instabilidade econômica, com consequências desastrosas sobre o conjunto da sociedade, notadamente sobre as condições de vida da população pobre.

Analisando essa questão, Silva, Yazbek e Giovanni (2008, p. 28) afirmam que, ao aderir ao movimento neoliberal, o Estado brasileiro assumiu "como principal função a de [um] Estado ajustador da economia nacional à economia internacional” e, nesse cenário, a Constituição Federal tornouse uma espécie de empecilho ao desenvolvimento. O neoliberalismo recria, assim, as condições sociais instáveis experimentadas na ascensão da modernidade, e, mais uma vez, o mundo entra em ebulição a partir das transformações orientadas para o mundo produtivo, o mundo do trabalho.

A opção pelo ajuste econômico no Brasil, como em outros países, sobretudo nos denominados emergentes, teve como consequência a estagnação do crescimento econômico e a precarização e instabilidade do 
trabalho, o desemprego e o rebaixamento do valor da renda do trabalho, com consequente ampliação e aprofundamento da pobreza, que se estende, inclusive, para os setores médios da sociedade. (SILVA; YAZBEK; GIOVANNI, 2008, p. 27)

O mercado de trabalho, desde a criação dos primeiros mecanismos de proteção social no Brasil, que remonta aos anos 1930, sempre funcionou como um mecanismo de inclusão e simultaneamente de exclusão social. Desde essa época, "ser cidadão significava ter carteira [de trabalho] assinada e pertencer a um sindicato". (SILVA; YAZBEK; GIOVANNI, 20o8, p. 26) Na década de 1990, o desemprego estrutural e a precarização dos postos de trabalho, associados à reformulação do perfil dos trabalhadores exigidos pelo novo estágio da produção, tornaram-se os elementos excludentes por excelência, e as condições de vida a que a maior parte da população se vê colocada põem em xeque a noção de cidadania. Como observa Ivo (2008, p. 188), "opera-se [...] uma ruptura estrutural entre os planos social, econômico e político”.

Essa autora demonstra como a reorientação da agenda social em torno da luta pela erradicação da pobreza produz uma separação entre pobreza e trabalho, desconsiderando as causas estruturais do fenômeno, tomando as causas como efeitos e colocando a questão social e de enfrentamento da pobreza "fora do âmbito dos seguros e direitos sociais dos trabalhadores". (IVO, 2008, p. 172) ${ }^{17}$ As políticas de transferência de renda focalizada, adotadas nos anos 1990, se dão, assim, "à margem do campo da proteção social” e constituem-se em "ações de urgência, de caráter mitigador e compensatório da assistência à pobreza, para grupos selecionados”. (IVO, 2008, p. 187)

Seguindo uma abordagem semelhante, Silva, Yazbek e Giovanni (20o8) analisam os PTR no bojo do Sistema de Proteção Social e corroboram o fato de a adoção desses programas dar-se num contexto em que o modelo Welfare State não responde mais às questões sociais, de enfrentamento à pobreza e ao desemprego. Esses autores entendem que a concepção de políticas de transferência de renda, ou mais especificamente dos programas sociais dessa natureza, orienta-se por distintas perspectivas teóricas: na perspectiva neoliberal, são, de fato, programas de cunho compensatório

17 Para acessar as discussões iniciais sobre esse tema no Brasil, ver Anete Brito Leal Ivo. Metamorfoses da questão democrática, 2001. Disponível em: <http://bibliotecavirtual.clacso.org.ar/ar/libros/ ivo/ivo.html>. 
e residual, substitutos de formas complexas de proteção; de uma perspectiva distributiva, os programas têm caráter inclusivo e complementar aos serviços básicos prestados pelo Estado; por fim, uma perspectiva de transitoriedade entende esses programas como medida necessária à inserção profissional e social.

Partindo desses elementos, os autores julgam possível "desvendar o significado do desenvolvimento histórico e a natureza desses programas no Brasil" (SILVA; YAZBEK; GIOVANNI, 20o8, p. 43), destacando a possibilidade de duas perspectivas teóricas para o caso brasileiro:

c. uma perspectiva neoliberal em favor do mercado, que toma os programas como residuais e compensatórios, num quadro social de exclusão e desemprego, tido como inevitável, e orientando-se, assim, para "a focalização na extrema pobreza, para que não ocorra desestímulo ao trabalho” (SILVA; YAZBEK; GIOVANNI, 2008, p. 43); e

d. uma perspectiva da "cidadania universal" ou "redistributivista", com focalização positiva para a inclusão digna de todos.

Considera-se que as pioneiras experiências locais, desenvolvidas em alguns municípios brasileiros e no Distrito Federal, tinham essa perspectiva cidadã, mas, após a ampliação ao âmbito nacional, verificou-se a migração para um matiz neoliberal, de modo que os resultados obtidos "parecem direcionar-se para a criação de um estrato de pobres situados num patamar de indigência ou de mera sobrevivência”. (SILVA; YAZBEK; GIOVANNI, 2008, p. 44) Uma constatação, aliás, feita também por Ivo (2008, p. 201), considerando que a focalização em segmentos selecionados da população cria uma "hierarquia de categorias de posições de proteção", estratos de cidadania que se convertem em "formas de reconhecimento social".

Essa situação, contudo, segundo Silva, Yazbek e Giovanni (2008), sofre um corte a partir do ano 2004, com a implementação do Programa Bolsa Família que, adicionado a um conjunto de outras medidas, como o reajuste regular do valor do salário mínimo, promove transformações positivas no quadro da distribuição de renda. O debate sobre a transferência de renda no Brasil é classificado por esses autores em cinco distintos momentos, dos quais os dois últimos compõem-se da implementação dos programas na- 
cionais, sendo um bloco formado por aqueles do final do governo Henrique Cardoso, entre 2001 e 2002, de marcada perspectiva neoliberal, e o outro do governo Lula, a partir de $2003,{ }^{18}$ com transformações quantitativas e qualitativas para a "construção de uma Política Pública de Transferência de Renda”. (SILVA; YAZBEK; GIOVANNI, 2008, p. 99) O “carro chefe” dessa política é o Programa Bolsa Família, que a partir de outubro de 2003, através da Medida Provisória no 132, passou a unificar os quatro principais programas existentes, três deles instituídos no governo anterior: Bolsa Escola, Bolsa Alimentação e Auxílio Gás, e o Cartão alimentação, instituído na nova gestão. No mesmo processo foi arrolado o Cadastro Único do Governo Federal, cuja operacionalização constitui o objeto do presente estudo.

Ao analisar o PBF, Anete Ivo (2008) o faz cotejando com os princípios de Seguridade postulados na Constituição Federal. A “reconversão” (2004) a que ela se refere diz respeito ao padrão da transição de princípios universalistas de um Estado de Bem-estar incompleto para a adoção de programas focalizados e flexíveis. Este processo envolve algumas características, como uma retórica em favor da pobreza e na desconstrução da seguridade social; uma ênfase na monetarização da assistência através das transferências monetárias diretas; uma divisão de responsabilidade entre o Estado e a sociedade etc. Ela conclui mostrando que o resultado desse processo significou os limites do conflito redistributivo restrito à base da pirâmide social e de renda (2004). Em relação aos princípios que orientaram a concepção dos direitos sociais na Constituição de 1988, a autora distingue os direitos sociais básicos à assistência de caráter constitucional, como o BPC, dos programas focalizados, como o Bolsa Família. (IVO, 2008)

O BPC, colocado em vigor a partir de 1996, mas criado pela Constituição de 1988, representa a concessão de "um salário mínimo de benefício mensal à pessoa [deficiente] e ao idoso que comprovem não possuir meios de prover à própria manutenção ou de tê-la provida por sua família”. (BRASIL, 1988, Art. 203) Ivo (2008) destaca características básicas que diferenciam esses programas: a primeira está no valor do benefício concedido, que, no caso do BPC, é de um salário mínimo, o qual, em 2008, período da análise, era de $\mathrm{R} \$ 415,00$, podendo representar, por sua interpretação, uma mudança qualitativa no padrão de vida das famílias beneficiárias; enquanto

18 Para detalhes dessa classificação, ver Silva, Yazbek e Giovanni, 2008, cap. II. 
o Bolsa Família tem seus limites mínimo e máximo, para o mesmo período, estabelecidos em $R$ \$20, oo e $R$ \$182, oo respectivamente, variando segundo seus critérios de seleção e concessão. Para a autora, a limitação do valor do benefício abaixo de um salário mínimo estabelece um limite de ascensão, "segmentando esses beneficiários no limite da pobreza". (IVO, 2008, p. 193) Mas a principal característica de diferenciação destacada pela autora está na condição de "direito" do BPC, que não contempla o PBF.

O Bolsa Família é um programa que associa à transferência de renda feita pelo Estado uma contrapartida das famílias beneficiárias, as chamadas “condicionalidades", referentes à realização de "exame pré-natal, ao acompanhamento nutricional, ao acompanhamento de saúde, à frequência escolar de 85\% (oitenta e cinco por cento) em estabelecimento de ensino regular”. (BRASIL, 2004b, Art. $3^{\circ}$ ) Esse elemento faz com que o Programa seja considerado por alguns como sendo de natureza transversal, de promoção do "acesso a direitos sociais básicos", como forma de "combater a miséria e a exclusão social” para a "emancipação” dos beneficiários. (WEISSHEIMER, 2006, p. 25) Considerando essas características e a extensão de sua cobertura, Weissheimer (2006, p. 26), por exemplo, afirma que o Bolsa Família inaugurou "uma nova agenda social no Brasil.

Embora a análise desse autor esteja ancorada em alguns dados de avaliação do Programa, é necessário cautela ao tomá-lo em tão elevada condição. A exigência de cumprimento das condicionalidades, por exemplo, contradiz as condições postas para o acesso aos serviços de saúde e educação. É possível admitir, como fazem Silva, Yazbek e Giovanni (2008, p. 139), que essa exigência possa desempenhar um peso simbólico importante para "romper com o viés assistencialista" dos programas sociais, mas, como observa Ivo (2008, p. 196), a deficiência na prestação desses serviços "pode estabelecer uma ralação de não- equivalência no 'contrato' entre os cidadãos e o Estado”. Obviamente, não se pode afirmar que haja aí necessariamente uma "quebra" de contrato, afinal, o que cabe ao Estado nessa relação, stricto sensu, é o repasse dos recursos, o que se faz regularmente. Mas essa é uma situação reveladora da desvinculação entre a execução do Programa e os direitos constitucionais que, ao lado do funcionamento regular da transferência de renda, seguem deficitários. Mas Ivo (2008) também ressalta que esse processo pode ter um efeito positivo, se vier a incidir sobre a ação governamental como estímulo à correção das deficiências. 
Há também o problema dos valores referenciais para o Programa. Em 2001, quando o Bolsa Escola foi lançado, a linha de corte para seleção de beneficiários era de $\mathrm{R} \$$ 90,oo per capta mensal, então metade do salário mínimo. (BRASIL, 2001d) O Bolsa Alimentação tinha a mesma referência, famílias com renda de zero a meio salário mínimo per capta mensal. (BRASIL, 20oij) O Auxílio Gás também tinha como linha de corte meio salário mínimo per capta. (BRASIL, 2002b) E o Cartão Alimentação, criado já pelo novo governo, em 2003, também sustentou a mesma referência. (BRASIL, 2003a) Ou seja, até a criação do Bolsa Família, a linha de pobreza, tomada por linha de corte para seleção de beneficiários dos PTR que foram nele unificados, era de meio salário mínimo. O PBF, porém, estabeleceu um valor desvinculado do salário, e classificou seus beneficiários em "pobres" - com renda per capta mensal de até R \$100,00 - e “extremamente pobres" - com renda per capta familiar de $\mathrm{R} \$ 50,00$. Isso, em 2003, equivalia a 41,7\% e 20,8\% do salário mínimo respectivamente; em 2004, 38,4\% e 19,2\%; e em $200533,3 \%$ e $16,6 \%$. A partir de 2006 , os valores começaram a ser elevados, mas longe de alcançar a antiga linha de referência, principalmente em razão dos reajustes reais e regulares do salário mínimo, que fez aumentar a distância entre os parâmetros.

Silva, Yazbek e Giovanni (2008) consideram preocupante esta que chamam de "redução drástica" no valor de referência, principalmente por sua desvinculação do parâmetro salarial, que pode redundar numa crescente redução dos parâmetros de definição da pobreza e indigência no país. Anete Ivo (2008), por sua vez, ainda tendo como referência a natureza da redistribuição e o montante da transferência, considera também que os reduzidos valores pagos pelo Bolsa Família revelam a subordinação das políticas sociais aos ajustes da política econômica. Ademais, a dissociação dos valores do parâmetro do salário mínimo estabelece desigualdades em relação a outros benefícios e pode, em caso de não reajuste, rebaixar o patamar de sobrevivência.

Mas o Bolsa Família não se diferencia dos programas anteriores unicamente por suas referências monetárias, afinal, embora a linha de corte de parte daqueles programas tivesse um parâmetro definido, ancorado no salário mínimo, os benefícios pagos não eram também significativos. O PBF aprimora a focalização, pois a gradação dos benefícios restringe o seu público-alvo. Está clara a opção pela população “extremamente pobre”, que tem um benefício básico garantido, independente do cumprimento de condi- 
cionalidades. É, sem dúvida, um programa importante e necessário, pois da mesma forma que a fé sem obras é morta, como afirma a mensagem bíblica (BÍBLIA , 1990, Tg 2: 17), ${ }^{19}$ pouco vale reconhecer a existência de miseráveis e delegar unicamente à necessidade de construção de mudanças estruturais a resolução de sua situação. A fome não espera! Mas isso não faz do Programa a solução da pobreza, como a propagandização de seus resultados sugere.

Por fim, é importante ressaltar um dado aparentemente controverso nesse refinamento da focalização feito pelo Bolsa Família. Embora o Programa restrinja metodologicamente o seu foco, seus resultados demonstram que ele aumenta a abrangência da cobertura. Ao estabelecer uma espécie de "piso mínimo de renda familiar no país", como analisa Almeida (2004, p. 15), o PBF incorpora uma ampla parcela da população que não se enquadrava nos critérios anteriores, por não ter crianças ou gestantes na família, por exemplo, ou que não era alcançada pelos programas devido a uma série de questões, dentre as quais o estabelecimento de cotas de cadastramento de beneficiários. Como isso é fruto de uma focalização cada vez mais precisa sobre um público específico, a forma de identificar esse público se torna, assim, a chave de funcionamento do Programa.

19 "Meus irmãos, se alguém diz que tem fé, mas não tem obras, que adianta isso? Por acaso a fé poderá salvá-lo? Por exemplo: um irmão ou irmã não têm o que vestir e lhes falta o pão de cada dia. Então alguém de vocês diz para eles: 'Vão em paz, se aqueçam e comam bastante’; no entanto, não lhes dá o necessário para o corpo. Que adianta isso? Assim também é a fé: sem as obras, ela está completamente morta”. (BÍBLIA, 1990, Tg 2: 14-17) 